\title{
Gel-foam granuloma in the brain
}

\author{
G. T. G. KNOWLSON \\ From the University Department of Neuropathology, Manchester
}

\begin{abstract}
SYNOPSIS A case is recorded in which a large giant cell reaction to gel-foam is noted after its use in neurosurgery. This caused blockage to the flow of cerebrospinal fluid and also thrombosis of superficial vessels of the brain with subsequent infarction. We recognize the value of gel-foam as a haemostatic agent in neurosurgery but wish to warn against its use too close to viable cerebral tissue, as it can induce a marked giant cell granulomatous reaction.
\end{abstract}

Iatrogenic foreign body reactions have been described in most situations in the body. Those which are caused by talcum (magnesium silicate) crystals have been well documented, especially if they occur in the peritoneal cavity. Others have occurred in response to silica, berylium, and zirconium and numerous other substances. In the nervous system they are not common but have been reported after the use of bone wax and the introduction of lipiodol into the spinal theca.

Gel-foam has been used as a haemostatic agent in surgery for many years and most reports are favourable (Corell et al., 1945; Pilcher and Meacham, 1945; Blaine, 1951). This case report indicates a possible danger in the use of gel-foam particularly in enclosed cavities as in the central nervous system, where the production of a voluminous foreign body reaction may produce unexpected sequelae.

\section{CASE HISTORY}

A male patient aged 42 years had suffered with progressive grand mal seizures, irritability, and headaches for some years. Recently, some papilloedema had developed and his visual acuity had deteriorated. A skull radiograph showed calcification in the right frontal lobe and a brain scan and carotid angiograms showed the presence of a space occupying lesion. An oligodendroglioma was removed. Haemostasis in the area was secured with the help of gelfoam. After a normal postoperative period the patient returned home.

Three weeks after his discharge the patient was readmitted with frontal headache, nausea, and vomiting and a swelling over the bone flap. On examina- tion he was drowsy and there was moderate papilloedema. The operation site was re-explored.

The operation note states: 'Inspection of the frontal polar region showed the previous site of operation and here a clean operative cavity was encountered. The problem was immediately apparent in that the escape routes for cerebrospinal fluid from the operative cavity had been obliterated by the gel-foam used to line the cavity and surrounding bleeding margins'.

A further resection of the lobe was performed and the specimens were sent for histological examination.

HISTOLOGICAL FEATURES The overlying dura mater was adherent to scar tissue (Fig. 1). A central vessel had undergone thrombosis and recanalization. Above this there was gel-foam and a surrounding giant cell reaction. Below and to the left the brain had undergone infarction and numerous microglial granular phagocytes were seen in association with astrocytic reaction. Above and to the right there was an area of scar tissue. Figure 2 shows the gel-foam associated with a marked giant cell reaction, underlying fibrosis, and microglial reaction in the brain. Examination of deeper tissue revealed the residual oligodendroglioma which was known to have been left behind at the earlier operation.

\section{DISCUSSION}

Adverse reactions to gel-foam have not been recorded before as it is normally used to secure haemostasis in areas where any reaction it produces will have few side-effects or will go unnoticed.

Gelatin sponge is essentially a dried gelatin 


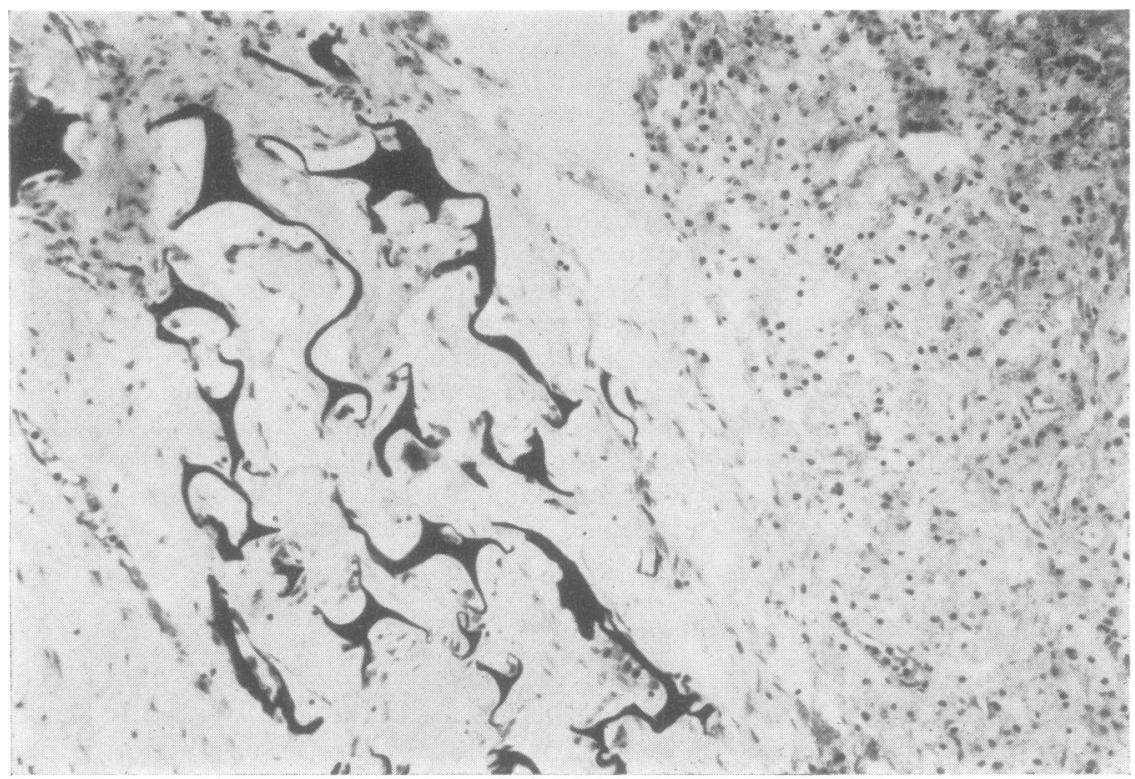

FIG. 1. Thrombosed and recanalized vessel close to gelfoam, and underlying infarction of the brain.

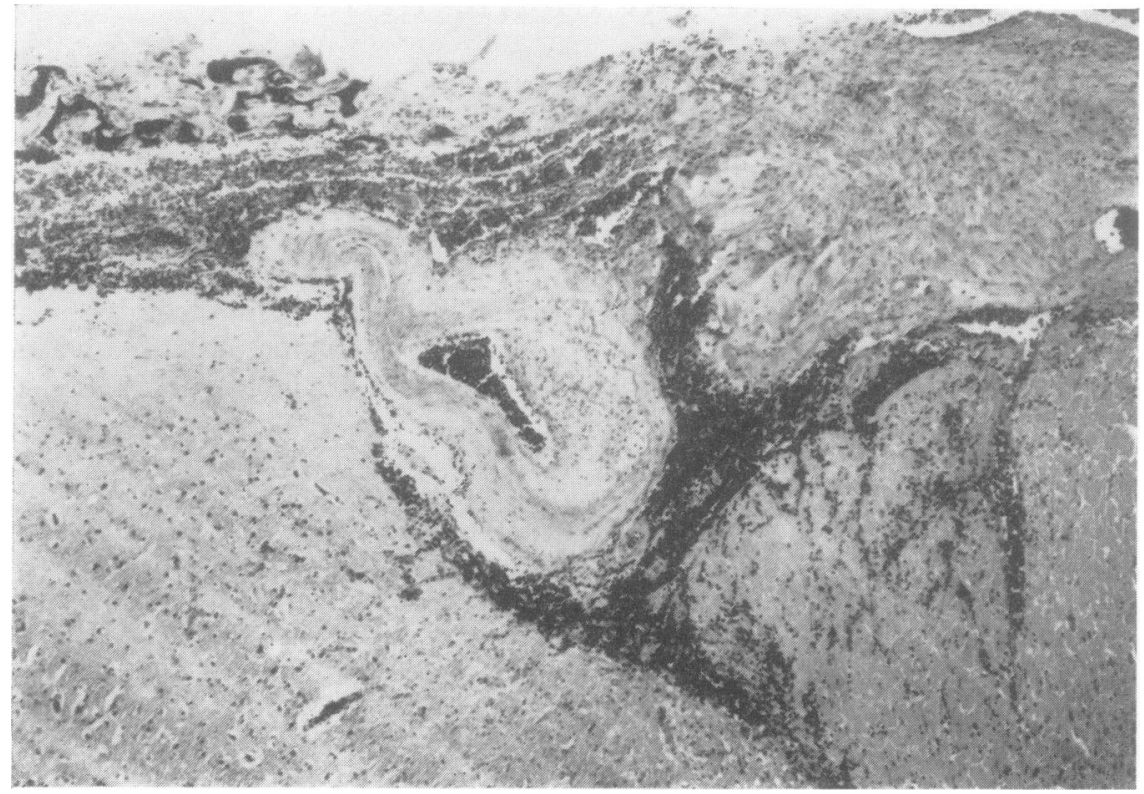

FIG. 2. Giant cell reaction to gel-foam with underlying infarcted brain.

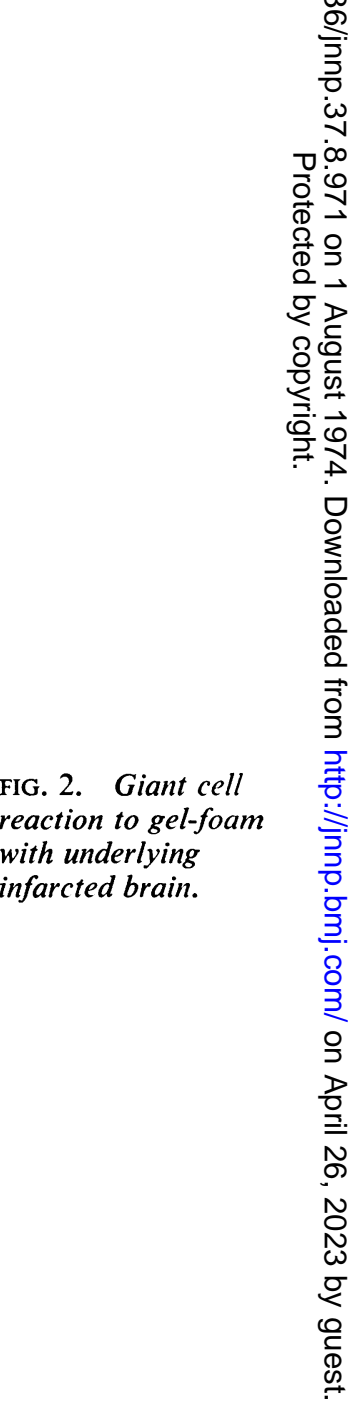


foam made by beating and whipping a sterile and lightly formolized gelatin solution into a foam of uniform porosity. When this is dried under suitable conditions it retains its original porous structure. The dried material is cut into the required sizes and shape and sterilized at $160^{\circ} \mathrm{C}$.

Blaine (1951) studied the effects of the gelfoam in animal muscle and liver and reported his histological findings. He found that by the 11 th day the gel-foam was surrounded by fibroblasts, round cells and some giant cell systems were visible, and the gel-foam itself was in an advanced stage of digestion. He concluded that gelatin sponge is absorbed or organized in approximately four to six weeks, always provided that too large an implant had not prevented the access of phagocytes. The only previously recorded adverse reaction was by Shenoi (1973) who found that the formaldehyde incorporated with the sponge caused sensorineural hearing loss in stapedectomy patients.

This report is an attempt to warn against the use of gel-foam in the cranial cavity in situations where the giant cells and fibroblastic reaction can be disadvantageous. The granulomatous reaction can be so marked as to cause an increase in the intracranial pressure or, as in this case, unforeseeable sequelae. Blaine (1951) stated that care should be taken to avoid the use of large volumes of gel-foam which would increase the giant cell reaction in any area. Light and Prentice (1945) found that the brain surface showed no appreciable reaction but we have noted that the reaction may involve the superficial blood vessels causing them to undergo thrombosis with subsequent infarction of the underlying brain.

It seems pertinent, therefore, to warn against the use of gel-foam in enclosed cavities where the enormous giant cell reaction may be harmful. While appreciating its value in other sites in the cranial cavity, we would advise against its use in cerebral tissue itself.

I am grateful to Professor P. O. Yates for his help in the preparation of this paper and to Mr J. Dutton for his permission to quote one of his cases.

\section{REFERENCES}

Blaine, G. (1951). Absorbable gelatin sponge in experimental surgery. Lancet, 2, 427-429.

Correll, J. T., Prentice, H. R., and Wise, E. C. (1945). Biological investigations of a new absorbable sponge. Surgery, Gynecology and Obstetrics, 81, 585-589.

Light, R. U., and Prentice, H. R. (1945). Gelatin sponge. Archives of Surgery, 51, 69-77.

Pilcher, C., and Meacham, W. F. (1945). Absorbable gelatin sponge and thrombin for hemostasis in neurosurgery. Surgery, Gynecology and Obstetrics, 81, 365-369.

Shenoi, P. M. (1973). Ototoxicity of absorbable gelatin sponge. Proceedings of the Royal Society of Medicine, 66, 193-196. 